\title{
Utilising Online Gamification to Promote Student Success and Retention in Tertiary Settings
}

\author{
Ingrid Harrington $^{1} \&$ Marc J. Mellors ${ }^{1}$ \\ ${ }^{1}$ School of Education, University of New England, NSW, 2351, Australia \\ Correspondence: Ingrid Harrington, School of Education, University of New England, NSW, 2351, Australia.
}

Received: May 9, 2021

Accepted: June 12, 2021

Online Published: June 15, 2021

doi:10.5430/ijhe.v10n7p45

URL: https://doi.org/10.5430/ijhe.v10n7p45

\begin{abstract}
The role of gamification in Australian higher educational learning has gained increasing currency in recent years, with many proponents promoting its usefulness for improving the university student experience by increasing progression and lowering attrition, particularly among first year students (Charles, Charles, McNeill, Bustard, \& Black, 2011). However, some students express reservations that the inherently competitive nature of some gamified learning activities negatively impact their learning experience, especially when compared to classic instructional methods (Charles et al., 2011). This discussion and instructional paper undertakes a review of the gamification literature within the Australian higher education context, concurrently exploring what it means and how to use gamification to enhance student learning. The paper provides a short biographic summary of the positive impact selected popular gamified activities has had on improving student engagement, participation and retention in tertiary settings.
\end{abstract}

Keywords: gamification, higher education, tertiary education, student success, retention

\section{Introduction}

The concept of gamification is not new: humans have evolved as socially competitive animals, and games and competitive play have played a central role in the human experience for millennia (Huizinga, 1944). Gamification should be thought of as "the concept of using game-based mechanics, aesthetics and game thinking to engage people, motivate action, promote learning, and solve problems" (Kapp, 2012). The concept of competitive games and game playing provides an ideal platform in light of self-determination theory (Ryan \& Deci, 2000), that outlines how people need to experience feelings of competence, autonomy, and relatedness in order to thrive psychologically (Burguillo, 2010; Ryan \& Deci, 2000). Kapp (2012) described the impact of gamified features in an educational setting as "provid[ing] the right mix of engaging elements from games like a sense of progress or immediate feedback, and visible signs of improvement over time with content to motivate". Structural gamification i.e. the inclusion and application of game-elements to assist a student through the content with no alteration or changes to the content, is the best approach when first implementing gamification in learning activities, because its effectiveness can be regularly evaluated by qualitative means such as verbal feedback, surveys and assessment results (Hunicke, Leblanc, \& Zubek, 2004). If improvements are observed in these domains, then it might be worth investigating a more in-depth content change to courseware that incorporates gamification theory in a more substantial way. Structural gamification's continual, real-time assessment of student progress provides vital information to both educators and students, specifically, student knowledge acquisition, enjoyment and engagement with content (Morrison, Ross, Kemp \& Kalman, 2010).

From an educator's perspective, incorporating gamification theory into learning promotes the incentivisation of traditionally non-gaming activities and experiences such as learning, in the same way it does traditional game experiences such as competitive play (Australian Commonwealth Department of Education, 2020). It does this by harnessing extrinsic and intrinsic motivators to act as catalysts for peoples' desires to find intrinsic fulfilment and feelings of self-worth (Lamb, Annetta, Firestone \& Etopio, 2018; Ryan \& Deci, 2000). The question is however, how effective is gamification in practice within the higher educational setting to promote engagement and learning? Currently, the 'ultimate rewards' or incentives for tertiary students are the Learning Outcomes (LO's), and the unit material and assessment is the 'game'. A well designed 'game' can be described as "a system in which players engage in an abstract challenge, defined by rules, interactivity, and feedback, that result in a quantifiable outcome often eliciting an emotional reaction" (Kapp, 2012). As such, the learning designers and subject matter experts essentially work out the rules for any particular course or game, so that it is not only compelling, but also effective in delivering 
the intended LO's. Accordingly, games embedded in educational activities should be designed to reward behaviours, drive success, create lasting excitement, and engage students on an emotional level (Hunicke, Leblanc, \& Zubek, 2004).

\subsection{COVID-19 Considerations}

The COVID-19 pandemic highlighted within global tertiary settings how blended learning environments that typically comprise a mix of face-to-face and distance delivery of courseware, were presented with a challenging pedagogical environment from learning and instructional design perspectives. Traditionally, there has been a tendency to treat learning environments primarily as a face-to-face experience, with some ad hoc accommodations for distance students to engage with the same material in the way of lecture recordings and online content (Gordon, 2014; Kapp, 2012). Some blended learning environments are driven by technology for its own sake, and seem to sacrifice the much needed 'personal touch' feature found in traditional face-to-face learning environments (Parker, Robinson, \& Hannafin, 2008). Kapp and Cone (2012) report how educators need to recognise and 'keep up' with their students' preferred learning pathways i.e. students who engage extensively in video/computer games and other IT activities typically find the more traditional methods of learning involving page turning and e-learning modules, lacklustre and not engaging. From this aspect, introducing gamification into a 'traditional' learning space becomes an opportunity rather than meeting a learning requirement, as it recognises and takes advantage of the experience, habits and preferences of many new students. Gamification therefore becomes a strategy recognising and utilising students' preferred methods of communication, collaboration and learning (Gordon, 2014). Access to continual feedback from assessment and progress helps the educator identify strengths and weaknesses with unit design and assessment structure (Gordon, 2014).

\section{Gamification in the Australian and Wider International Settings}

The role of gamification in Australian educational environments is gaining more governmental recognition with the Australian Commonwealth Department of Education (DoE) issuing guidelines on effective implementation strategies, particularly in the national Primary and Secondary STEM curricula via its National STEM Education Resources Toolkit (DoE, 2020). However, the DoE urges caution when implementing gamification activities, as it recognizes that the results from various studies are 'mixed' and not representative with regards to gamification's efficacy in producing better learning outcomes, and also notes that most gamification research has focused on tertiary students' learning outcomes (Australian Commonwealth DoE, 2020).

From an international perspective, the role of gamification in learning has been under increasing study over the last decade, with one meta-analysis of 46 experimental studies reporting that the overall results for introducing gamified elements into the classroom, manifest as increases in student achievement, cognition, and affect (Lamb, et.al., 2018). These positive results in the classroom are an encouraging sign and highlight a challenge for distance and online educators to achieve similar outcomes in this delivery mode. Additionally, within the global context, rising attrition and lowering retention rates in tertiary settings has been a concern over the past decade, with universities considering a range of responses to directly impact the increasing trend of student attrition (Farr-Wharton, et.al., 2017; Kahu and Nelson, 2018; Li and Carroll, 2020). If any positive changes in student attrition and retention are to be realised, tertiary educators need to think more creatively, broadly and differently to their current teaching and engagement challenges. Educators need to strive to provide inclusive opportunities for all students to learn that promote curiosity, are goal-oriented, relevant, and broad in application, and where the transference and application of skills are highly valued (Ashman, 2010; Morrison, st.al., 2010; Richardson, 2011). This discussion paper will explore the advantages, variety, interest and enjoyment embedding gamified activities in tertiary settings can bring both the educator and students.

\section{Applying Gamification in Tertiary Teaching Contexts}

Research reports that the broad range of gamification techniques are effective in both face-to-face and distance delivery models, so when used astutely and appropriately, they can easily integrate into the tertiary blended learning environment (Alabassi, 2018; Kapp, 2012; Morrison, et.al., 2010). Incorporting gamification in the blended learning environment can be as simple as a structural change to the way existing content is delivered, or as challenging as a complete overhaul of course content (Morrison, et.al., 2010). Embedding gamification into existing content is adaptable due to its flexible nature, and has the added benefit of being easily implemented in both face-to-face and online learning activities (Gordon, 2014; Ryan \& Deci, 2000). One of gamification theory's greatest appeals is its scalability, flexibility, and adaptability (Gordon, 2014). Gamification is scalable because key strategies and activities can be initially incorporated into aspects of a teaching session, and easily expanded to encompass larger sections of the courseware (Gordon, 2014). Gamification is flexible because it appeals to such deeply intrinsic drives in the human psyche, i.e. competitive behaviour and the 'desire to excel', that almost any element of a course activity can be 
modified to appeal to these drives by providing effective motivational triggers, such as positive reinforcement via external feedback and rewards (Ryan \& Deci, 2000).

\subsection{Limiting Factors of Gamification}

As with any novel approach or significant pedagogical change, introducing gamification strategies in teaching might not prove to be either effective or successful. It is critical to understand that some learning outcomes might not be achievable with gamification, so classical teaching techniques will still need to be utilized (Lean, Moizer, Towler \& Abbey, 2006). Tertiary educators need to take into consideration the nature of the topic, associated unit objectives, and their choice of pedagogies, to determine which gamified activities would best enhance student learning and engagement (Kahu \& Nelson, 2018; Lamb, et.al., 2018). Acknowledging the difference each teaching topic presents and are best taught utilising particular pedagogies, the flexibile nature of gamification may provide avenues of success for tertiary learners (Parker, Robinson, \& Hannafin, 2008).

The broad range of gamified activities available are both novel and interesting, and can add significant advantages in the correct and appropriate subject context (Kapp, 2012). When incorporating game elements into instruction, the educator's focus needs to be on what makes games meaningful, rather than how novel they may be in the learning context (Nebel, Beege, Schneider, \& Daniel, 2016). Game elements that promote effective instruction include continual corrective feedback, storytelling, challenges, and the opportunity to fail (Goff \& Higbee, 2008). The use of games, points, badges and leaderboards are also significant aspects of the instructional and pedagogical design. Gamification of learning content via the use of leaderboards, badges, and story-based narratives is fairly widespread, but the key drive to implement gamification in learning tasks must always be informed and dependent upon well-defined learning objectives (Nebel, et.al, 2016). Despite the broad range of appeal that gamified activities may offer tertiary educators and their students, it appears that the incorporation of gamified activities across all tertiary learning areas has not been widely embraced in the teaching of tertiary students in the $21^{\text {st }}$ century (Australian Commonwealth DoE, 2020).

\section{Gamification Philosophy in Learning}

The research is abundant as to the advantages and benefits incorporating gamification into traditional learning environments can bring (DoE, 2020; Burguillo, 2010; Charles, et al. 2011; Gordon, 2014; Kapp, 2012; Nebel, et al., 2016). As such, gamification should be thought of as the concept of using game-based mechanics, aesthetics and game thinking to engage students, motivate action, promote learning, and solve problems (Kapp, 2012). Student engagement in games is driven by the challenge, excitement and the possibility of winning, so when embedding games within pedagogy, the focus needs to be on what makes games most meaningful (Charles, et.al., 2011; Parker, et.al., 2008). Promoting 'meaningfulness' into instructive and effective gamification activities typically encompass elements of corrective feedback, challenges and storytelling. In doing so, the games essentially engage, interact and are inclusive of the student in their learning, providing ongoing feedback on their performance, and mastery of the intended subject matter (Alabbasi, 2018; Ashman, 2010; Burguillo, 2010; Dylan, Clare, Harrison, \& Black, 2004). It is important to accept that failure must be an option in gamified activities, and needs to be explored when evaluating the effectiveness or usefulness of gamifying courseware. The option of failure is constructive in gamified activities, as failure allows the student to evaluate where they went wrong, and attempt to find success (Dylan, et.al., 2004; Kapp, 2012). Other advantages gamified learning offers include assisting in the retention and knowledge application by building higher order thinking skills, and promoting a sustained focus on engagement and participation (Australian Commonwealth DoE, 2020; Dylan, et.al., 2004; Kahu \& Nelson, 2018).

The sense of competition is a powerful motivator facilitated by the gamification paradigm, but caution is encouraged when implementing competitive elements in activity designs, as competition may lead to a lack of cooperation and even conflict in the worst-case scenarios (Kapp, 2012; Neble, et.al, 2016). Gamification theory aims to encourage healthy low-stakes competition and place emphasis in shared learning experiences to foster teamwork and collaboration (Lamb, et.al., 2018). It is typically better to set challenging cooperative game-based tasks that emphasize the importance of being able to work cooperatively, rather than head-to-head competitions, (English, et. al., 2007; Kapp \& O'Driscoll, 2010). The effective implementation of gamification attempts to guide the student from being a subject matter novice to subject mastery, and avoids the notions of winning and losing, and as such, educators need to promote mastery rather than winning. This is especially important when rewards are offered, as it can be easy for some students to fixate on the short-term progress rewards, and not the long-term reward of attaining the stated learning outcomes (Burguillo, 2010). Educators need to ensure that students can experience some degree of success with gamified activities, otherwise risk that important learning goals may not be met (Kapp, 2012). Central to learning is the 
level of student effort and struggle that may produce significant gains in intrinsic learning, which is something that can lead to higher student engagement and motivation (Neble, et.al, 2016; Ryan and Deci, 2000).

\section{Examples of Gamified Learning in Tertiary Settings}

There are many ways in which gamification can be successfully incorporated into tertiary settings. The following section provides a brief overview of a condensed selection of a number of gamified techniques and activities, that have contributed to measurable degrees of success in blended learning, including badges, point systems, leaderboards, discussion boards, narratives, polls and boardgames. A description of their nature, type, advantages, disadvantages, and areas for tertiary educators to be mindful of when implementing them, are flagged for consideration.

\subsection{Badges}

Badges have been used to reinforce scaffolded learning activities where each badge represents a significant step or completion of a section in the course, with a capstone badge awarded for completing a related set of badges. Badges and other micro rewards such as points and leaderboards, have been popular activities in teaching as they provide strong extrinsic motivation for students to excel and complete activities (Charles, et.al., 2011; Lamb, et.al., 2018). In tertiary settings, they typically are used to signpost a student's completion of sections that comprise a larger integrated unit; the badge is a visual reward and reminder of the student's achievement and progress. However, implementing badges and micro-rewards needs careful consideration because the aim of effective instructional design is to nurture an intrinsic motivation to learn, not just the desire for extrinsic reinforcement (Nebel, et.al., 2016; Ryan \& Deci, 2000). Caution must be used with badges, because the progress they represent needs to be significant enough that the badge's currency is not diminished due to being too easy to attain, or because there are too many of them (Hunicke, et.al., 2004; Lamb, et.al., 2018). Badges need to be valued by both students and the wider learning community, otherwise there will be no motivation to earn them, making them of little use or even redundant for motivating students.

\subsection{Points Systems}

The awarding of points for the engagement with, and completion of assessments and activities, can be a powerful motivator for learning (Gordon, 2014). As students progress through unit information, they earn points concurrently as they complete tasks or assessments. The overt awarding of points offers an immediate 'just in time' feedback system, that can be extremely beneficial for students to discover quickly how they are tracking within the module itself, and the course overall in real time (Neble, et.al., 2016). The possibility to re-attempt activities should factor into any design using a points-based question or activity. By offering another attempt at activities, the educator essentially creates secondary marking factors that will reward the student for completing a task in a shorter period of time or with more accuracy. As such, the educator can motivate the student to evaluate previous attempts, revise the material, and aim for an improved score the next time they engage with the activity (Morrison, et.al., 2010). However, implementing points and scoring meaningfully into learning tasks may be problematic, and common pitfalls such as embedding a multitude of extrinsically driven rewards and 'shallow' learning outcomes are best identified and avoided. For example, instead of simply awarding points for answering a question correctly, a student could gain points for the degree of 'correctness' displayed in their answer. This means that the educator needs to design a scale of correctness for a question that may motivate the student to engage with the learning material more deeply, in order to attain more points (Clark \& Martinez-Garza, 2012).

\subsection{Leaderboards}

Leaderboards are another common element of gamified learning and can be highly effective when used in the correct learning context (Burguillo, 2010; Kapp, 2012; Nebel et al., 2016). Whilst engaging with learning material, students earn rankings either in marks, peer votes or fastest times, and leaderboards publically list student places and achievements on the learning mainframe. Whilst many people enjoy the competition of seeing how they compare against their peers, there is a significant proportion of people who dislike this public form of competition, and whose learning may seriously be hampered because of it (Charles, et al., 2011). As such, leaderboards should ideally be used on an opt-in basis, and are probably not appropriate used as part of an assessment task. Leaderboards are good discussion starters amongst team members that can be utilized to not only discover knowledge gaps, but also formulate subject mastery tasks to address them in order improve their leaderboard standing (National Research Council, 2009; Virk, Clark, \& Sengupta, 2015). Similar to badges and points, leaderboards may provide significant extrinsic motivation, so the key is to convert the extrinsic motivation into the more desirable intrinsic type (Ryan \& Deci, 2000). The activities that feed into leaderboard standings should be relevant to the unit's learning outcomes, and the learning task needs to be developed first, and only then should its appropriateness for an assigned value towards a leaderboard be assessed (Morrison, et.al., 2010). 
In order to avoid leaderboards from demotivating students ranked relatively low in the field, it may be useful to display the contextual standing of students by displaying only the five higher and lower scores (Kapp, 2012). By doing this, the student is motivated to improve their score to surpass their immediate peers without being identified, rather than face the task of rising many places to reach the top ten. Another effective way to avoid any negative consequences a leaderboard may have on a student's motivation is to create group or team leaderboards. These may take the pressure off individuals and also encourage collaboration amongst students to drive their team's standing up the leaderboard (Clark \& Martinez-Garza, 2012; Clark, Sengupta, \& Virk, (2016).

\subsection{Discussion Boards}

Discussion boards are another way that educators can embed gamification concepts into their learning material, to provide students with other avenues to achieve their learning objectives. In their simplest form, badges and point-rewards may be awarded to students for meeting requirements set for any given task e.g. creating thread-starter posts, replying to a specific number of other students' posts, or demonstrating they are an 'influencer' of some kind (Bronack, 2011). For forum-based gamification techniques to be effective, they should encourage real discussion and not simply represent a 'tick the activity completion box for credit' mentality (Clark, Tanner-Smith \& Killingsworth, 2015). Discussion boards and forums may be useful learning tools for the exchange of ideas, so any gamified elements need to reinforce the free flow of ideas, and perhaps offer a 'hidden' reward when the necessary criteria have been met. This 'Easter Egg' approach (Kapp, 2012) is another gamification technique whereby students are informed of hidden rewards, but only vague or cryptic hints are offered for how to unlock them. This strategy tries to offer the necessary extrinsic motivator, but does not prioritise it at the expense of the learning activity.

\subsection{Narrative-Driven Gamification}

The use of narratives to create a strong story-driven context into a learning activity that incorporates a sense of mystery may empower and motivate students to engage deeper with learning material (Clark \& Martinez-Garza, 2012; Lamb, et.al., 2018; Nebel et. al., 2016), and has been shown to encourage students to explore learning material in new and innovative ways (Kapp, 2012). Students' imaginations may also be captured by fantasy elements which often provide better memory 'hooks' for learnt material, because the student has committed the material to memory alongside powerful mental imagery (Clark \& Martinez-Garza, 2012). Creating these memory hooks is an extremely desirable learning outcome, because it not only facilitates the transmission of information from working memory to long-term memory, but it facilitates its re-call when needed (Ebner \& Holzinger, 2007). Narrative-based gamified activities also trigger a sense of autonomy and self-determination in students, which empowers them to explore the learning material themselves, thus developing the all-important intrinsic learning motivation (Hunicke, et. al., 2004; Kapp, 2014; Ryan $\&$ Deci, 2000).

\subsection{Polls}

The real-time polling of students can be an effective way to shape the way learning content is delivered (Hoban \& Hastings, 2006; Kapp \& O’Driscoll, 2010). Educators may design polls in the form of surveys where they invite students to provide feedback on current learning agendas or future teaching implementions. One of the key tenets of gamification, as informed by Self-Determination Theory, is to inspire a student's intrinsic desire to engage with courseware through extrinsic motivators (Ryan \& Deci, 2000). By taking polls, the educator has an opportunity to adapt and deliver their materials in interesting and new ways, by optimizing the way that they present the extrinsic motivators to students. (Clarke, et.al., 2015; Dunlap, 2005). Using polls to determine the direction of instruction presents many potential challenges for lesson planning, but by remaining flexible and adaptive with a learning activity's direction, educators may be able to 'fill in the gaps' in their students' knowledge, by letting them reveal those knowledge gaps for themselves. Educators need to commit time to constructing meaningful polls, as using too many may result in student fatigue reflected in the declining quality of responses and numbers (Lean, Moizer, Towler \& Abbey, 2006).

\subsection{Board Games}

Board game designs can be a particularly useful way of embedding learning goals into an activity, especially for knowledge and procedural information that needs to be memorised (Imlig-Iten \& Petko, 2018; Lean, et.al., 2006). Creating flashcards and memory games in association with points and leaderboards, can be an especially powerful way of not only 'chunking' the information into easily memorized portions, but creating the necessary external 'hooks' needed to effectively retrieve the information from a student's long-term memory (Ebner \& Holzinger, 2007; Kapp, 2012). The advantages are numerous: board games are novel, fun, and fuel healthy peer competition, and whilst 
establishing the activity may take a great deal of time, once the activity is established, the educator has this activity to duplicate in future units.

This section has explored a number of gamified activities that tertiary educators may find positively influence the levels of their student engagement, enjoyment and learning of learning material. Educators need to contemplate the choice, type, placement and duration of any gamified activity into their existing units, if students are to enjoy the benefits of gamified learning.

\section{Summary and Future Directions}

This discussion paper has briefly explored some of the advantages of utilizing gamification techniques in learning activities, with an overriding motivation to encourage a discussion of the feasibility of implementing gamification elements in a blended learning environment. Discussion of the merits of gamification and how it can improve access and participation for all students highlighted its value in tertiary settings. The benefits and range of healthy competitiveness gamified learning can offer tertiary educators and their students, may inspire other tertiary educators to consider incorporating gamified activities to improve the student learning and engagement experience.

Research has noted that most studies have focused on tertiary students' successful attaining of academic learning outcomes (Cunninghame, Costello, \& Trinidad, 2016; DoE, 2020). Therefore, further research into the benefits of gamification on critical learning domains, such as student engagement, knowledge retention and improved assessment outcomes, is needed at all levels of Australian education, but with a particular urgency in the primary and secondary environments. Other future research directions that would shed additional light on the benefits of gamified activities in learning include research measuring the effectiveness of various and/or specific gamification techniques to specific topic areas. Additionally, conducting a pilot of existing units implementing one or more gamified elements, to measure shifts in student engagement, learning, enjoyment, retention and success, would also inform the literature on gamification in teaching and learning.

\section{References}

Alabbasi, D. (2018). Exploring Teachers' Perspectives towards Using Gamification Techniques in Online Learning. The Turkish Online Journal of Educational Technology, 17(2), 34-45. Retrieved from https://files.eric.ed.gov/fulltext/EJ1176165.pdf

Ashman, A. (2010). Modelling inclusive practices in postgraduate tertiary education courses. International Journal of Inclusive Education, 14, 667-680. https://doi.org/10.1080/13603111003778429

Australian Commonwealth Department of Education. (2020). Gamification. Retrieved from https://www.education.gov.au/national-stem-education-resources-toolkit/gamification.

Australian Institute of Health and Welfare. (AIHW). Disability in Australia: Changes over Time in Inclusion and Participation in Education. Cat. no. DIS 69. Canberra: AIHW. https://www.aihw.gov.au/getmedia/34f09557-0acf-4adf-837d-eada7b74d466/Education-20905.pdf.aspx

Barnard-Brak, L., \& Sulak, T. (2010). Online versus face-to-face accommodations among college students with disabilities. American Journal of Distance Education, 24, 81-91. https://doi.org/10.1080/08923641003604251

Black, P., Harrison, C., Lee, C., Marshall, B., \& William, D. (2003). Assessment for Learning: Putting it into Practice. Berkshire: Open University Press.

Brown, J., Collins, A., \& Duguid P. (1989). Situated cognition and the culture of learning. Educational Researcher, 18(1), 32-42. https://doi.org/10.3102/0013189X018001032

Bronack, S. (2011). The role of immersive media in online education. The Journal of Continuing Higher Education, 59(2), 113-117. https://doi.org/10.1080/07377363.2011.583186

Bryans Bongey, S., Cizadlo, G., \& Kalnback, L. (2010). "Blended solutions: Using a supplemental online course site to deliver universal design for learning (UDL)", Campus-Wide Information Systems, 27(1), 4-16. https://doi.org/10.1108/10650741011011246

Burguillo, J. (2010). Using game theory and Competition-based Learning to stimulate student motivation and performance. Computers \& Education, 55, 566-575. https://doi.org/10.1016/j.compedu.2010.02.018

Charles, D., Charles, T., McNeill, M., Bustard, D., \& Black, M. (2011). Game-based feedback for educational multi-user virtual environments. British Journal of Educational Technology, 42(4), 638-654. https://doi.org/10.1111/j.1467-8535.2010.01068.x 
Clark, D., \& Martinez-Garza, M. (2012). Prediction and Explanation as Design Mechanics in Conceptually Integrated Digital Games to Help Players Articulate the Tacit Understandings They Build through Game Play. Games, learning, and society: Learning and meaning in the digital age, p.279.Clark, D., Sengupta P., Brady, C., Martinez-Garza, M., Killingsworth S. (2015). Disciplinary integration of digital games for science learning. International Journal of STEM Education, 2(1), 1-21. https://doi.org/10.1017/CBO9781139031127.023

Clark, D. Tanner-Smith, E., \& Killingsworth S. (2015). Digital games, design, and learning a systematic review and meta-analysis. Review of Educational Research. 26937054.

Cunninghame, I., Costello, D., \& Trinidad, S. (2016). "Issues and Trends for Students with Disability." National Centre for Student Equity in Higher Education, Curtin University. https://www.ncsehe.edu.au/wp-content/uploads/2016/08/Issues-and-Trends-for-Students-with-Disability-Revie w-of-NCSEHE-Funded-Research.pdf

Dunlap J. C. (2005). Problem-based learning and self-efficacy: How a capstone course prepares students for a profession. Educational Technology Research and Development, 53(1), 65-83. https://doi.org/10.1007/BF02504858

Dylan, W., Clare, L., Harrison, C., \& Black, P. (2004). Teachers developing assessment for learning: Impact on student achievement. Assessment in Education, 11, 49-65. https://doi.org/10.1080/0969594042000208994

Ebner, M., \& Holzinger, A. (2007). Successful implementation of user-centered game based learning in higher education: An example from civil engineering. Computers \& Education, 49(3), 873-890. https://doi.org/10.1016/j.compedu.2005.11.026

Farr-Wharton, B., Charles, M., Keast, R., Woolcott, G., \& Chamberlain, D. (2017). Why lecturers still matter: The impact of lecturer-student exchange on student engagement and intention to leave university prematurely. Higher Education, 75(1), 167-185. https://doi.org/10.1007/s10734-017-0190-5

Goff, E., \& Higbee, J. (Eds.) (2008). Pedagogy and student services for institutional transformation: Implementing universal design in higher education. Minneapolis: Centre for Research on Developmental Education and Urban Literacy, University of Minnesota.

Gordon, N. (2014). Flexible Pedagogies: technology-enhanced learning. Retrieved from https://www.hv.se/globalassets/dokument/stodja/paper-theme-3.pdf

Griful-Freixenet, J., Struyven, K., Verstichele M., \& Andries, C. (2017). Higher education students with disabilities speaking out: perceived barriers and opportunities of the Universal Design for Learning framework, Disability \& Society, 32(10), 1627-1649. https://doi.org/10.1080/09687599.2017.1365695

Hall, T., Meyer, A., \& Rose, D. (2012). Universal design for learning in the classroom: Practical applications. New York, NY: Guilford Press.

Hoban, G., \& Hastings, G. (2006). Developing different forms of student feedback to promote teacher reflection: A 10-year collaboration.Teaching and Teacher Education, 22(8), 1006-1019. https://doi.org/10.1016/j.tate.2006.04.006

Huizinga, J. (1944). Homo Ludens: A Study of the Play-Element in Culture. London, Great Britain. Routledge and Kegan Paul. Retrieved from http://art.yale.edu/file_columns/0000/1474/homo_ludens_johan_huizinga_routledge_1949_.pdf

Hunicke, R., Leblanc, M., \& Zubek, R. (2004). MDA: a formal approach to game design and game research. In Proceedings of the AAAI Workshop on Challenges in Game AI, (pp. 04-04). Retrieved from http://www.cs.northwestern.edu/ hunicke/MDA.pdf

Imlig-Iten N. Petko D. (2018). Comparing serious games and educational simulations: Effects on enjoyment, deep thinking, interest and cognitive learning gains. Simulation \& Gaming, 49(4), 401-422. https://doi.org/10.1177/1046878118779088

Kahu, E., \& Nelson, K. (2018). Student engagement in the education interface: Understanding the mechanisms of student success. Higher Education Research and Development, 37(1), 58-71. https://doi.org/10.1080/07294360.2017.1344197

Kapp, K. (2012). The Gamification of Learning and Instruction: Game-Based Methods and Strategies for Training and Education. San Francisco, CA: John Wiley and Sons. https://doi.org/10.1145/2207270.2211316 
Kapp, K., \& Cone, J. (2012). What every Chief Learning Officer needs to know about Games and Gamification for learning, Department of Instructional Technology and Institute for Interactive Technologies. White Paper.

Kapp, K., \& O'Driscoll, T. (2010). Learning in 3d: Adding a new dimension to enterprise learning and collaboration. San Francisco, CA: John Wiley an

Lamb, R., Annetta, L., Firestone, J., \& Etopio, E. (2018) A meta-analysis with examination of moderators of student cognition, affect, and learning outcomes while using serious educational games serious games, and simulations. In Computers in Human Behaviour, 80, 158-167. https://doi.org/10.1016/j.chb.2017.10.040

Lean, J., Moizer, J., Towler, M., \& Abbey, C. (2006). Simulations and games: Use and barriers in higher education. Active Learning in Higher Education, 7(3), 227-242. https://doi.org/10.1177/1469787406069056

Li, I., \& Carroll, D. (2020). Factors influencing dropout and academic performance: An Australian higher education equity perspective. Journal of Higher Education Policy and Management, 42(1), 14-30. https://doi.org/10.1080/1360080X.2019.1649993

Madaus, J., Banerjee, M., McKeown, K., \& Gelbar, N. (2011). Online and blended learning: The advantages and the challenges for students with learning disabilities and attention deficit/hyperactivity disorder. Learning Disabilities: A Multidisciplinary Journal, 17, 69-76.

Morrison, G., Ross, S., Kemp, J., \& Kalman, H. (2010). Designing effective instruction. Hoboken, NJ: Wiley.

National Research Council. (2009). National Research Council Workshop on Games and Simulations. Washington DC: National Academies Press.

National Network of Libraries of Medicine. (2020). UDL for Teaching Face-to-Face and Online. Retrieved from https://news.nnlm.gov/nto/2018/03/05/udl-for-teaching-face-to-face-and-online/.

Nebel, S., Beege, M., Schneider, S., \& Daniel, G. (2016). The higher the score, the higher the learning outcome? Heterogeneous impacts of leaderboards and choice within educational videogames. Computers in Human Behaviour, 65, 391-401. https://doi.org/10.1016/j.chb.2016.08.042

Parker, D., Robinson, L., \& Hannafin, R. (2008). "Blending" technology and effective pedagogy in a core course for preservice teachers. Journal of Computing in Teacher Education, 24, 49-54.

Richardson, S. (2011). Uniting teachers and learners: Critical insights into the importance of staff-student interactions in Australian university education: AUSSE Research Briefing v.12 ACER.

Ryan, M., \& Deci, E. (2000) Self-determination theory and the facilitation of intrinsic motivation, social development, and well-being. American Psychologist, 55(1), 68-78. https://doi.org/10.1037/0003-066X.55.1.68

Schelly, C., Davies, P., \& Spooner, C. (2011). Student perceptions of faculty implementation of Universal Design for Learning. Journal of Postsecondary Education and Disability, 24, 17-30.

Virk, S., Clark, D., \& Sengupta, P. (2015). Digital games as multi-representational environments for science learning: Implications for theory, research, and design. Educational Psychologist, 50(4), 284-312. https://doi.org/10.1080/00461520.2015.1128331

\section{Copyrights}

Copyright for this article is retained by the author(s), with first publication rights granted to the journal.

This is an open-access article distributed under the terms and conditions of the Creative Commons Attribution license (http://creativecommons.org/licenses/by/4.0/). 